\title{
REUTILIZAÇÃO E RECICLAGEM: DESENVOLVIMENTO DE JOIA COM COMPONENTES ORIUNDOS DE RESÍDUOS ELETROELETRÔNICOS
}

\section{REUSE AND RECYCLING: DEVELOPMENT OF JEWELRY WITH ELECTRONIC WASTE-BASED COMPONENTS}

LUCIO SILVA KIELING CINTRA | UFSM

MARIANA KUHL CIDADE, Dra. | UFSM

\begin{abstract}
RESUMO
Na sociedade contemporânea, o consumo acelerado gera o investimento cada vez maior em tecnologias, e como consequência, o aumento de resíduos de equipamentos eletroeletrônicos (REEE). Em diversas situações o descarte desses resíduos não é feito de forma totalmente eficaz. Como papel do designer atualmente engloba todo o clico de vida do produto, e não somente a produção e consumo, o presente artigo tem como objetivo apresentar uma proposta para a reutilização e reciclagem de REEE através da produção de uma peça joalheira contemporânea. O projeto consiste em uma revisão de literatura a respeito de resíduos eletroeletrônicos, desmonte de celulares para averiguação de possíveis alternativas de utilização dos componentes em joalheria e a produção da peça final. A pesquisa permitiu constatar a quantidade e variedade de recursos que podem ser reutilizados a partir de resíduos eletroeletrônicos. Porém, também se percebe a dificuldade de reutilização destes recursos, devido à grande variedade e complexidade dos materiais envolvidos, assim como o uso excessivo de materiais em alguns casos.
\end{abstract}

PALAVRAS CHAVE: Reutilização; reciclagem; resíduos eletroeletrônicos; joalheria contemporânea; sustentabilidade.

\begin{abstract}
In contemporary society, accelerated consumption generates increasing investment in technologies, and consequently, the increase of Waste Electrical and Electronic Equipment (WEEE). In many situations the disposal of such waste is not completely effective. Since the role of the designer currently encompasses the entire life cycle of the product, not just production and consumption, this article aims to present proposals for the reuse and recycling of WEEE through the production of a contemporary jewelry. The project consists of a literature review about electro-electronic waste, disassembly of cell phones to investigate possible alternatives for using the components in jewelry and production of the final piece. The research showed the amount and variety of resources that can be reused from electrical and electronic waste. However, it is also perceived the difficulty of reusing these resources, due to the great variety and complexity of the materials involved, as well as the excessive use of materials in some cases.
\end{abstract}

KEYWORDS: Reuse; recycling; electro-electronic waste; contemporary jewelry; sustainability 


\section{INTRODUÇÃO}

Com o aumento na frequência de uso de novas tecnologias, produtos com diferentes funcionalidades despertam a atenção do consumidor, o qual muitas vezes não pensa duas vezes antes de adquirir a novidade. Esse contexto de aumento do consumo está diretamente ligado com questões de sustentabilidade (ASHBY, 2013). Ao consumir em uma velocidade mais rápida do que o processo de recuperação de recursos naturais, o processo torna-se insustentável, o que é evidenciado pela pegada ecológica de Wackernagel e Rees (1996). A média de consumo de recursos naturais por cada habitante do planeta Terra deveria girar em torno de 2,2 hectares, segundo os autores. Entretanto, por exemplo, a média Europeia gira em torno de 4,8 hectares e a Americana atinge incríveis 9,6 hectares (DOUGHERTY, 2011). Evidencia-se assim o descompasso entre consumo e recuperação de recursos naturais. Com a velocidade de consumo aumentando, a questão do pós-consumo torna-se mais pertinente ao ciclo de vida dos produtos industriais, em particular os com maior complexidade, como os eletroeletrônicos. Desta forma, a gestão de resíduos, aqui nomeados, de acordo com Xavier e Carvalho (2014), resíduos de equipamentos eletroeletrônicos (REEE), tem sido motivada, no Brasil, por questões de ordem legal, social e ambiental.

A Política Nacional de Resíduos Sólidos (PNRS), regida pela Lei no 12.305, de 2 de agosto de 2010 (BRASIL, 2010), define que fabricantes, importadores, distribuidores e comerciantes, e consumidores de resíduos diversos, como baterias e componentes eletroeletrônicos, detém o encargo de implementar e operacionalizar um sistema de logística reversa, aplicando procedimentos de reinserção ao sistema produtivo de produtos ou embalagens usadas, através de processos como reciclagem e reutilização. Reciclagem define-se como o processo que altera características físicas, químicas ou biológicas dos componentes, enquanto reutilização é o processo que não altera essas características dos resíduos (BRASIL, 2010).

Diante desta situação, fabricantes de aparelhos celulares, como Samsung ${ }^{\oplus}$ (2018), LG ${ }^{\oplus}$ (2018), e Motorola ${ }^{\oplus}$ (2018), já apresentam programas de gestão de resíduos eletroeletrônicos em território brasileiro, alertando o consumidor sobre o descarte correto de seus produtos e indicando pontos de coleta. Porém, não é de tarefa apenas do setor empresarial a gestão de resíduos. De acordo com a PNRS (BRASIL, 2010), políticas públicas devem ser motivas pelo setor público, assim como adequada destinação de resíduos deve também ser implementada pelo consumidor. Em grande parte das regiões urbanas, surge, então, a instalação de centros de triagem, os quais caracterizam-se por locais total ou parcialmente subsidiados por prefeituras para realizar a separação e comercialização de resíduos sólidos urbanos (PALOMBINI; CIDADE; DE JACQUES, 2017). A Prefeitura da cidade de Santa Maria, na região central do estado do Rio Grande do Sul, apresenta uma relação de Pontos de Entrega Voluntária (PEVs) que recebem aparelhos eletroeletrônicos do município, entre outros materiais (PMSM, 2018). Estes resíduos são destinados a associações de reciclagem cadastradas junto ao município da cidade, onde são triados e destinados corretamente (PMSM, 2018). Entretanto, muitas vezes a falta de informação ou divulgação da existência destes PEVs ou de empresas recolhedoras de seus resíduos, acabam gerando uma destinação incorreta, por parte dos usuários, descartando estes em seus lixos domésticos ou muitas vezes misturando-os com o lixo orgânico (MORENO; CIDADE, 2019). Com o aumento do descarte destes equipamentos, percebe-se a importância de o designer atuar também como um agente de transformação, sendo seu papel não exclusivo apenas à efetivação do produto, mas englobando todo o ciclo de vida deste.

Apesar de iniciativas de fabricantes de telefonia móvel e de investimentos em políticas públicas, cenários como - Brasil ainda apresentam particularidades de mercado que carecem da atuação mais específica na gestão de resíduos eletroeletrônicos (XAVIER; CARVALHO, 2014). De acordo com a Agência Nacional de Telecomunicações (ANATEL, 2012), em 2011 o número de celulares já ultrapassava o número de habitantes no Brasil, como uma teledensidade de 123,87 acessos por telefonia móvel a cada 100 habitantes. Conforme Kasper et al. (2011), a obsolescência dos aparelhos celulares faz com que os usuários mantenham o aparelho em atividade de 9 a 18 meses. Estes dados sinalizam um tipo específico de produto que merece atenção quanto à efemeridade de seu ciclo de vida e, consequentemente, ao seu potencial crescimento como resíduo. Em eletrônicos desse tipo, uma variedade de componentes, definidos por materiais, processos de fabricação e elementos de junção diversos, formam um tipo de resíduo com grande complexidade em ser reutilizado ou reciclado. Por outro lado, a presença de materiais de grande interesse comercial, como o cobre, também pode representar um incentivo para seu reprocessamento (CÂNDIDO; KINDLEIN JÚNIOR; PALOMBINI, 2015).

A variedade de materiais que compõem os resíduos de equipamentos eletroeletrônicos é grande. Conforme Xavier e Carvalho (2014) e Widmer (2005), pode-se destacar a presença em termos de peso em REEE de ferro e 
aço (48\%), polímeros sem (15,3\%) e com (5,3\%) retardante de chama; cobre (7\%); vidro (5,4\%); alumínio (4,7\%); placas de circuito impresso (3,1\%); cerâmicos (2\%); entre outros. Conforme Moraes, Espinosa e Lucena (2014) e Ashby (2013), destaca-se a importância de variados métodos de recuperação destes por duas razões principais: a toxicidade, visto que muitos componentes apresentam riscos à saúde e ao meio ambiente, os quais são potencializados quando há desconhecimento de como administrá-los, bem como com relação ao consumo energético dos equipamentos ao longo da vida útil. A exemplo, é possível citar alguns componentes e seus elementos potencialmente perigosos, tais como as baterias, com a presença de chumbo $(\mathrm{Pb})$ e mercúrio $(\mathrm{Hg})$; placas de circuito impresso, com antimônio ( $\mathrm{Sb}$ ) em ligas de cádmio (Cd) em contatos e interruptores; visor de cristal líquido (LCD) com cerca de 20 substâncias distintas; entre outros (SEPA, 2011; ANDRADE-LIMA, 2012).

Uma parte importante dos aparelhos celulares, e rica em diversos elementos na sua composição, é a placa de circuito impresso (PCB - Printed Circuit Board) (KASPER et al., 2011). Segundo Huabo et al. (2010), a PCB é uma placa que comporta diversos componentes eletrônicos, e está presente em diversos aparelhos. No caso de aparelhos celulares, um terço da composição das placas é definida por metais, como o cobre, por exemplo (TAKANORI et al., 2009). Este se apresenta como o metal de maior concentração das placas, sendo usado na condução de energia do circuito. Destaca-se também a presença de metais nobres, como o ouro, prata e paládio, sendo usados como materiais de contato ou camadas de revestimento devido às suas propriedades de alta condutividade e estabilidade química (HUABO et al, 2010). Para a recuperação dos metais presente nas placas de circuito impresso dos apareIhos celulares existem alguns métodos específicos, como a pirometalurgia e a hidrometalurgia (YAN et al., 2016).

Nas últimas décadas tem crescido um movimento de utilização de materiais não convencionais para a fabricação de joias, sendo conhecida como joalheria contemporânea (CIDADE et al., 2016). A utilização de outros materiais, além de ajudar a reduzir o impacto ambiental, também amplia as oportunidades e a sustentabilidade dentro do mercado joalheiro (MALESKI et al., 2017). De modo geral, além de materiais inusitados, o estilo caracteriza-se pela busca de novas formas de apresentar joias com o emprego de processos e métodos diferenciados, resultando em peças valorizadas e com alto nível de acabamento (CIDADE, 2017). Desse modo, o presente artigo apresenta uma proposta para a recuperação de resíduos sólidos oriundos de aparelhos celulares e carregadores descartados, utilizando-os para a criação de uma nova peça aplicada à joalheria contemporânea. Primeiramente, são apresentados conceitos e exemplos de joalheria e em seguida o desenvolvimento do projeto, com uma gama de aparelhos selecionados, juntamente com seus carregadores fora de uso e/ou danificados, sendo desmontados e incluídos em uma peça por meio de reutilização e reciclagem.

\section{JOALHERIA}

Segundo Gola (2013), os sentidos carregados pela palavra joia se fazem presentes em "prazer", "objeto de amor" e "alegria". Já de acordo com Bueno (2000) denotativamente joia é uma espécie de artefato de matéria preciosa, contendo metais nobres e gemas. Em um sentido figurativo, a palavra expande-se para conceitos de pessoa ou coisa de grande valor, sendo algo apreciado e estimado (BUENO, 2000). Desse modo, este lado do conceito de joia dialoga com a ideia da peça como objeto de adorno.

No decorrer dos tempos, a joia assume valores distantes dos seus primórdios de significação, aparentando ser algo inconsistente e supérfluo (GOLA, 2013). Porém, sendo estudada a importância da joia como adorno para a manutenção da espécie e contexto sociocultural (GOLA, 2013), percebe-se a limitação do pensamento anterior. Adornar está relacionado com "ornamento" e "ornamentação". Conforme as definições do Instituto Brasileiro de Gemas e Metais (IBGM, 2012), adornos são objetos presentes na sociedade deste a pré-história, com a função de ornamentar o corpo de alguma forma. Sendo essas palavras oriundas do latim ornare, que significa "adornar" e inclusive "equipar", a joia como adorno vai além de um simples ato de adicionar algo, mas expande-se para melhoria e acréscimo de qualidade (GOLA, 2013). Assim, pode-se considerar a joia como importante objeto de estudo de significação.

A semiótica, área do conhecimento que estuda como os artefatos são capazes de transmitir conhecimento, apresenta o conceito de signo. Niemeyer (2013) caracteriza o signo como elemento capaz de ser percebido e assim transmitir significado referente a algum outro contexto ou objeto. Destaca-se assim, a joia como elemento de signo simbólico, sendo capaz de ser portador de diferentes concepções e sentimentos, atraindo-se para si caráter religioso, cultural e inclusive supérfluo (GOLA, 2013), como citado anteriormente. Além de ser elemento de estudo cultural, carregando junto de si concepções históricas, a joia também é capaz de transmitir uma afirmação pessoal do ser humano perante seus semelhantes (CORBETTA, 2007). 
Atualmente, a joia, dentro do contexto de joalheria, carrega junto de si variados significados, como na área da sustentabilidade. Segundo Gola (2013), a joalheria começa a ganhar outros rumos a partir da década de 50, quando o design de joias ganha formas inovadoras conectadas às novas tendências de movimentos e liberdades trazidas pela moda, destacando o uso de outros metais nobres, como a prata, e materiais pouco convencionais até então, como resinas, polímeros, ossos, madeiras, entre outros. Antes desse período, a prata, mesmo sendo um metal nobre, não era amplamente utilizada na confecção das peças (CIDADE et al., 2016), sendo vista como um material de pouco valor intrínseco. Diante da diversificação de materiais, a joalheria na contemporaneidade, de acordo com Cadore (2015), abre espaço para aliar o design sustentável na confecção de novas joias e adornos.

Além de materiais inusitados, a joalheria contemporânea mescla-se com a tendência atual do slow fashion. Segundo Cadore (2015), o slow fashion está relacionado com o consumo consciente e de acordo com as novas práticas sustentáveis. Nesse setor (Figura 01), pode-se elencar a o trabalho da joalheira Ashley Heather (Figura 01 A), da África do Sul, com a criação de brincos em prata coletada a partir de resíduos de placas de circuitos de eletroeletrônicos e a inserção de cimento para representar uma gema.

A

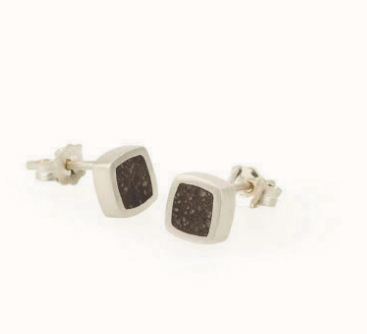

B
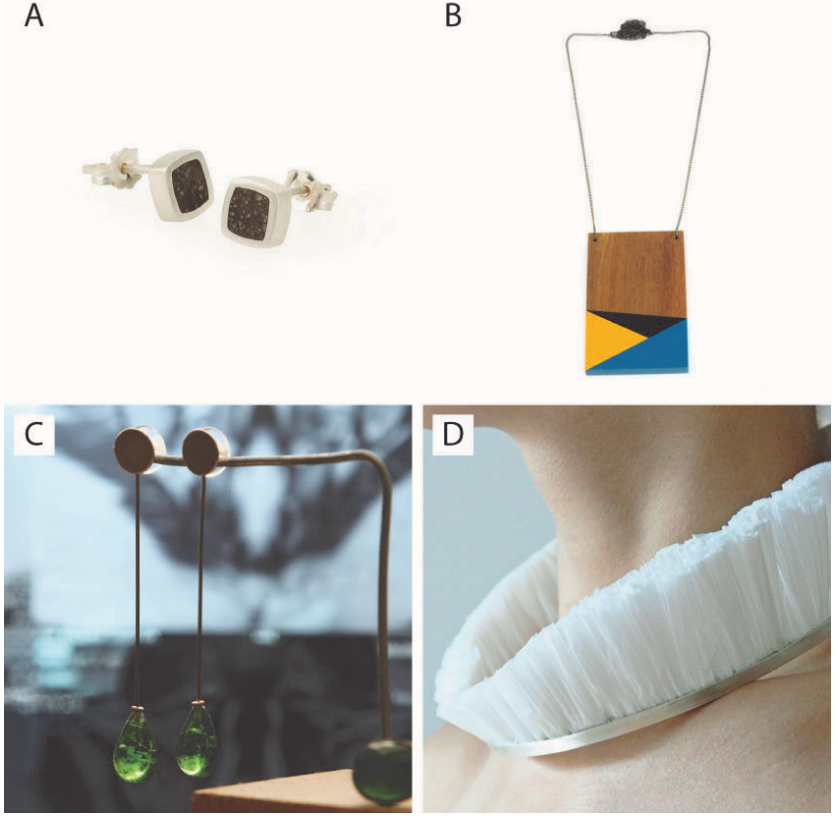

Figura 01 - Joias Sustentáveis: (A) brinco de prata recuperada de placas de circuito e cimento de Ashley Heather; (B) colar de madeira reutilizada, pintura com tinta acrílica e finalização com verniz da Crua Design; (C) joias de prata e vidro reciclado de Valéria de Sá e (D) adorno de sacolas plásticas de Malgosia Kalinska.

Fonte: Heather (2018), Crua Design (2018), Sá (2017) e Vogue (2010).
No cenário brasileiro, destaca-se as joias com resíduos de madeira da Crua Design (Figura 01 B), e as peças de prata extraída de placas de raio $\mathrm{X}$ e vidro reciclado da designer Valéria Sá (Figura 01 C). A designer Malgosia Kalinska, atualmente vivendo na Polônia, utiliza sacolas plásticas em suas criações, dando a cada peça um volume único (Figura $01 \mathrm{D}$ ).

Buscando o novo e a diferenciação, a joalheria contemporânea alia técnicas convencionais com novos processos, muitas vezes não só exclusivos a joalheria. Produz peças que conversam e representam novas tendências da atual sociedade, servindo como base para novas discussões e reflexões diante dos novos e múltiplos padrões do mundo contemporâneo.

\section{DESENVOLVIMENTO DO PROJETO}

Diante do grande número de aparelhos celulares no Brasil, e consequentemente de REEE, o presente artigo tem como proposta apresentar um uso para este material através da joalheria, agregando componentes de celulares descartados à metais nobres, no caso a prata (Ag 950). Após a coleta de informações pertinentes ao projeto, na parte introdutória e na fundamentação teórica, como a respeito dos resíduos eletroeletrônicos, partiu-se para a parte prática.

Para o desenvolvimento deste projeto, utilizou-se a metodologia de Löbach (2001) de forma adaptada, visto que para a criação de joias não existem metodologias especializadas. Com isso, o processo criativo foi delimitado por quatro etapas, sendo elas as fases de preparação, geração, avaliação e realização (LÖBACH, 2001). Na fase de preparação, foi analisado o problema, tendo o conhecimento do mesmo, onde se obteve informações sobre os resíduos e a sua desmontagem. Já para a geração de alternativas, a fase deu-se através do processo projetual, onde precisou-se ter em mente a junção da prata com as peças escolhidas após o desmanche dos celulares e carregadores. Após, foram avaliadas todas as alternativas para a escolha da peça joalheria, levando em consideração os objetivos e o problema, e iniciando a fase de realização, com a fabricação da joia. Todos os aparelhos celulares e carregadores deste artigo foram recolhidos de lixos domésticos e do descarte dos próprios autores.

\subsection{Desmonte das peças}

Para o desenvolvimento do projeto, foram coletados (Figura 02) 4 aparelhos celulares, 3 capas protetoras e 2 carregadores, visualizados respectivamente na Figura 02 $A, B$ e $C$. 

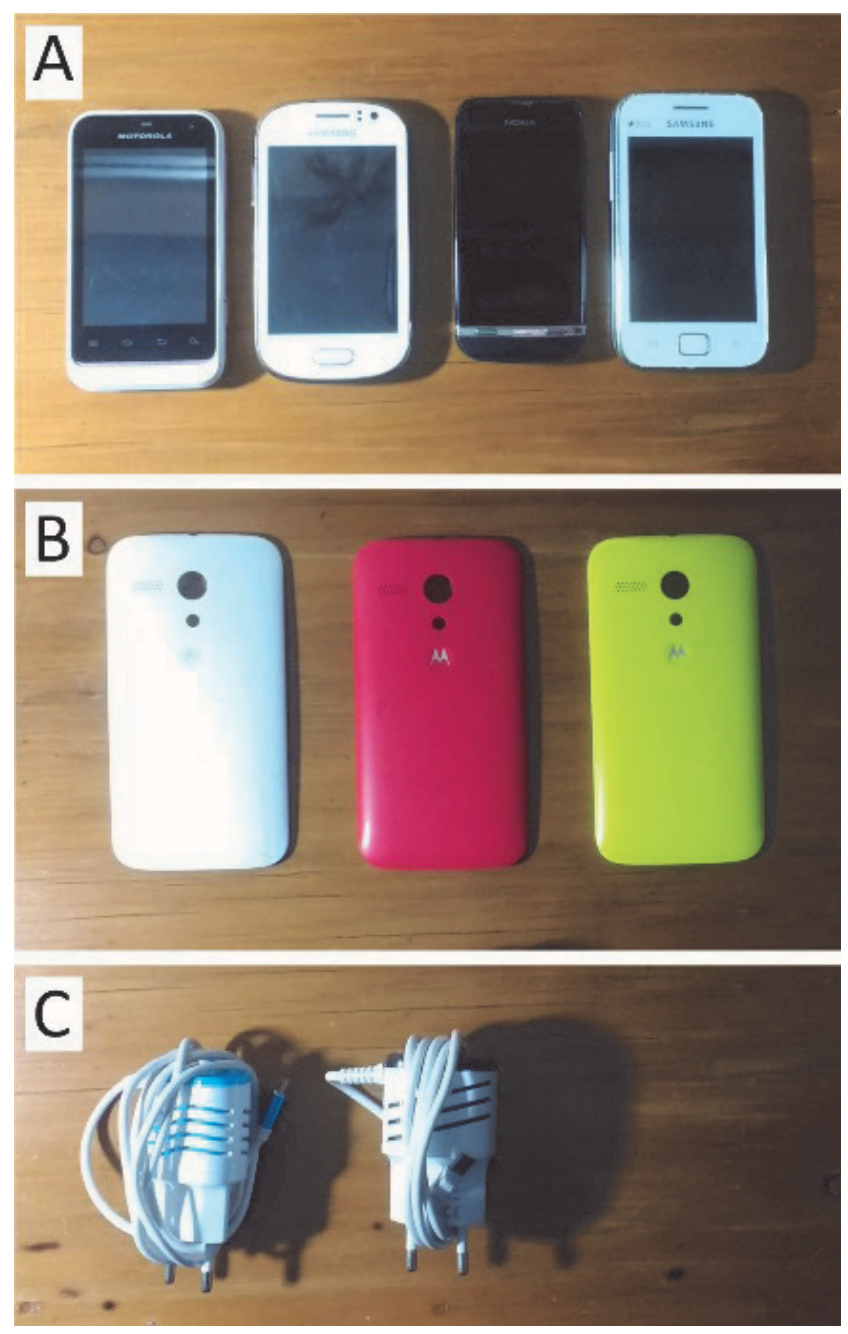

Figura 02 - Resíduos coletados: (A) celulares, (B) tampas e (C) carregadores. Fonte: Autores

Para o desmonte dos resíduos, devido aos seus componentes serem muitas vezes tóxicos e perigosos, utilizou-se luvas para efetuar o processo e optou-se pela reutilização dos componentes dos aparelhos celulares. $O$ único material que passou pelo processo de reciclagem foi o cobre, por não apresentar perigo à saúde. Este foi fundido posteriormente com a prata, como elemento de liga. Para o manuseio de um metal nobre, tanto a prata como o ouro, são necessários adicionar elementos para a formação de uma liga metálica. Esta adição visa a meIhorar suas propriedades físicas para posterior utilização.

Todos os produtos foram desmanchados (Figura 03) com a utilização de ferramentas manuais e sempre observando cuidadosamente os componentes potencialmente perigosos. Para estes componentes, como por exemplo, baterias e placas de circuito impresso, foi redobrada a atenção para que as ferramentas utilizadas não entrassem em contato com este tipo de material. Por esta razão, estes não foram serrados ou perfurados.

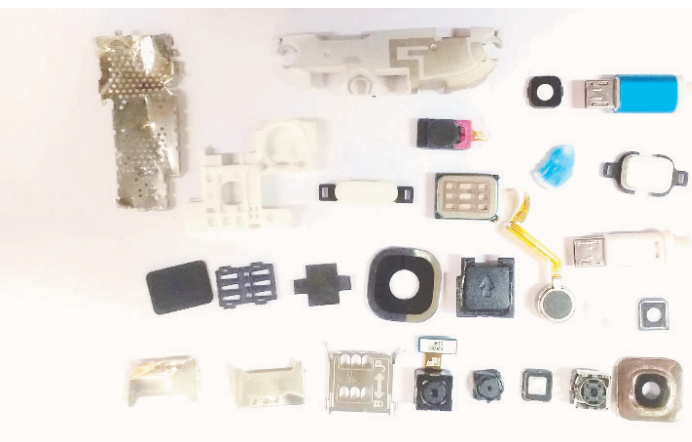

Figura 03 - Peças desmontadas Fonte: Autores

Após a desmontagem dos materiais, realizou-se a seleção das partes que poderiam ser utilizadas na joia, como os elementos contidos nos aparelhos celulares, tais como os módulos da câmera fotográfica, componentes USB, placas tanto metálicas como poliméricas, cabos, alto-falantes, suportes, plugs, entre outros. Além disso 4,8 gramas de cobre foram obtidos com o desmanche dos carregadores dos celulares, para ser reciclado como liga na prata.

\subsection{Processo Criativo}

Para o desenvolvimento do processo criativo, na fase de geração de alternativas, elaborou-se um painel semântico baseado em imagens da animação WALL.E ${ }^{\circledR}$ da Disney Pixar ${ }^{\oplus}$, visualizado na Figura 04. O filme traz como plano de fundo um futuro distópico em que a sociedade, devido ao grande acúmulo de resíduos, incluindo REEE, foi obrigada a abandonar a Terra.

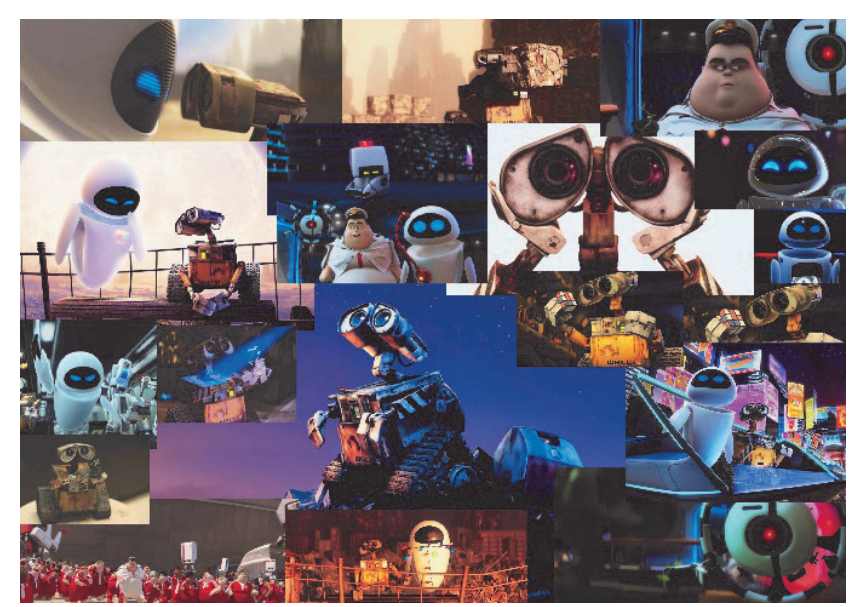

Figura 04 - Painel semântico

Fonte: Autores

Observando o tema, as formas do painel e as peças desmontadas dos celulares, foram realizados variados desenhos (Figura 05), buscando a conexão de todos os componentes. Para isso, utilizou-se de formatos mais simples, 
como círculos, retângulos, gotas, entre outros, para a base de metal em prata, adicionando os elementos do desmonte das peças, como partes das câmeras fotográficas, engate USB, lentes, alto-falantes e fios.

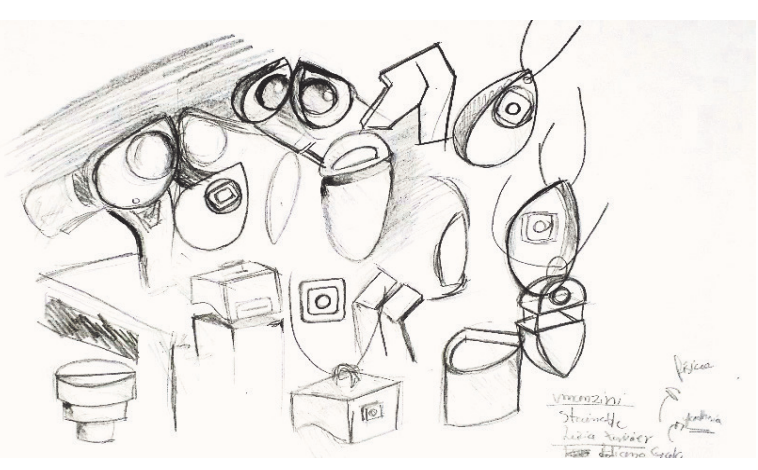

Figura 05 - Geração de alternativas Fonte: Autores

Com as inúmeras possibilidades de desenhos gerados, foi preciso seguir com a etapa de refinamento das alternativas. Desta forma, as alternativas foram sendo apuradas (Figura 06), para a posterior fabricação da peça. Entretanto, avaliou-se que a joia a ser desenvolvida neste projeto seria um pingente, devido ao formato e à quantidade de elementos que se obteve no desmonte dos aparelhos celulares. As
Por fim, para a realização da fabricação, delimitou-se as dimensões totais do pingente escolhido e onde e como os elementos dos REEE iriam ser acoplados.

\subsection{Processo de fabricação do pingente}

Para concepção do pingente, utilizou-se métodos da joaIheria artesanal, desenvolvendo a maior parte do projeto em bancada (Figura 07). Para a parte metálica delimitou-se a utilização da prata 950 que, conforme Kliauga e Ferrante (2009), apresenta uma liga de $95 \%$ de prata pura em sua composição, sendo o restante de cobre. O primeiro passo para a fabricação do pingente é a fundição da prata (Figura 07 A), onde o cobre utilizado foi retirado dos próprios resíduos, tanto dos celulares como dos carregadores. Como o desenho da peça compõe-se basicamente em formato de chapa, utilizou-se um laminador elétrico para conformar a prata permitindo, posteriormente, seu corte por meio de arco de serra (Figura 07 B e C). Ainda, duas partes do pingente possuem reforços de chapas de prata, como caixas para a cravação de gemas. Estes reforços irão acoplar os resíduos das partes da câmera fotográfica e do alto falante dos celulares desmontados. Na Figura 07 D, é possível visualizar um destes reforços já soldado à chapa metálica, indicado com uma seta branca. Para a junção dos resíduos escolhidos à prata, foi preciso uma união que não envolvesse perfurações e nem soldas a estes materiais. Esta escolha foi devido a possíveis materiais perigosos que poderiam estar alocados dentro destes componentes. Por esta razão, os componentes foram fixados com auxílio de cola adesiva.
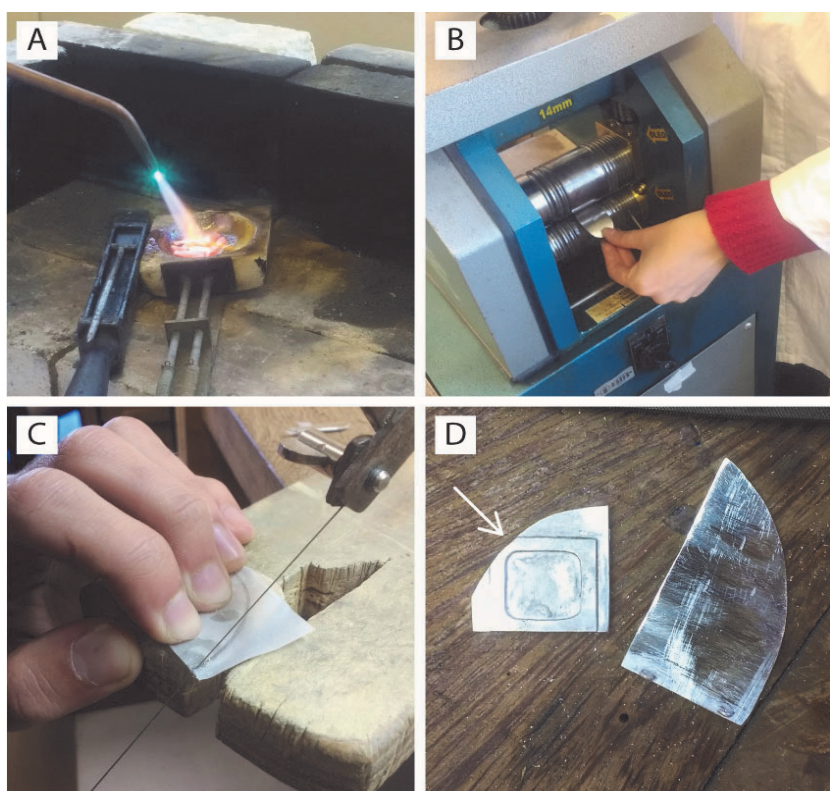

Figura 07 - Processo de produção do pingente: (A) fundição da prata e do cobre; (B) laminação da prata fundida em formato de chapa; (C) corte em bancada da chapa conforme a alternativa escolhida e (D) detalhe do reforço de prata soldado a chapa com indicação de seta branca. Fonte: Autores 


\section{RESULTADO}

O resultado alcançado com a utilização de elementos oriundos do descarte de aparelhos celulares e carregadores foi a materialização de uma peça joalheira contemporânea.

Durante o desenvolvimento do projeto, percebeu-se a dificuldade de reutilização e reciclagem do material em determinados momentos, pois alguns componentes dos aparelhos celulares não possibilitaram o desmonte. Algumas partes exigiam ferramentas muito específicas, o que pode ser visto com um entrave para o conserto ou troca de alguma parte dos celulares ainda em sua vida útil. Dessa forma, esse processo dificultou a retirada de alguns componentes e determinadas partes não puderam ser reutilizadas na peça final.

Diante dos componentes que poderiam ser reutilizados, escolheu-se aqueles que se adequavam à proposta da alternativa final. Além disso, o desenho da forma da peça também foi adaptado para o encaixe dos componentes com a prata. A peça é composta por duas grandes partes, uma como a cabeça do robô e a outra como o corpo. Para a união das duas, utilizou-se argolas de prata. A solução final (Figura 08) aproxima-se, assim, da figura de um robô baseando-se nos personagens da animação, como o tema deste projeto. Na Figura 08 A, B e C é apresentado o pingente finalizado, evidenciando os detalhes da peça. A Figura $08 \mathrm{D}$ é apresenta uma ambientação da peça final em meio à vários componentes que foram desmontados, enfatizando a quantidade de resíduos encontrados em apenas 4 celulares. Já na Figura 08 E, é exemplificado o pingente com uma corrente de prata para sua utilização. O resultado final apresenta-se como uma peça pertencente à joalheira contemporânea, utilizando materiais considerados pouco convencionais em harmonia com a prata, metal nobre clássico utilizado na joalheria.
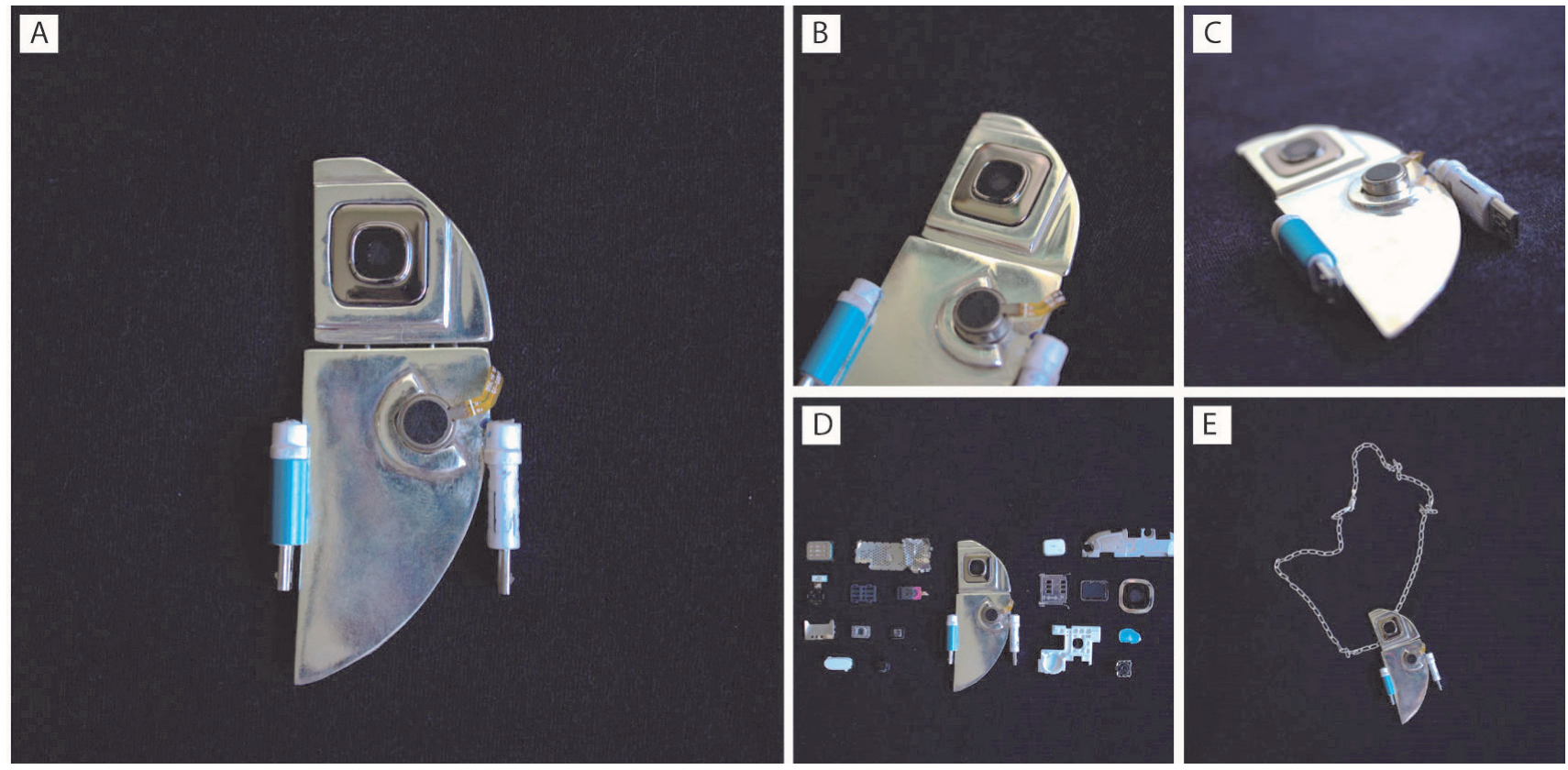

Figura 08 - Pingente desenvolvido: (A) peça finalizada; (B) e (C) detalhe da peça, (D) peça com componentes retirados para criação e (E) peça ambientada com corrente de prata. Fonte: Autores

\section{CONSIDERAÇÕES FINAIS}

Com o desmonte dos REEE, nesse caso celulares e seus carregadores, foi possível perceber algumas questões. Certas partes não possibilitaram o total desmonte ou desencaixe, pois precisavam de ferramentas especializadas, assim como alguns componentes apresentavam formas muito específicas, dificultando inclusive sua troca em caso de defeito do aparelho. Além disso, notou-se o uso demasiado de determinados materiais e componentes sem necessidade, como por exemplo, um excesso de elementos de fixação que, além de dificultar a desmontagem, contaminam os materiais para sua reciclagem. Por outro lado, a extração de cobre dos resíduos, principalmente dos fios, possibilitou a obtenção de uma quantidade razoável de material para utilização como elemento de liga na prata, favorecendo o processo de fabricação da joia. Mesmo com estas questões levantadas, os objetivos propostos por este artigo foram atingidos, pois foi possível desenvolver uma joia aliada aos princípios da sustentabilidade, de modo a aumentar a vida útil de determinados componentes, utilizando-os em um novo produto. 
Por fim, em uma sociedade mais diversificada, onde o consumo torna-se cada vez mais acelerado e ingênuo perante as questões sustentáveis, o designer surge como um agente capaz de projetar produtos alinhando diversos fatores, como sociais, ambientais e econômicos. Dessa for$\mathrm{ma}$, aliando técnicas tradicionais da ourivesaria com conceitos da joalheria contemporânea e materiais de descarte, o presente artigo destaca o designer como um profissional que projeta para uma sociedade de consumo, mas que também entende seus pontos não produtivos assim como as oportunidades, administrando não apenas questões de produção, mas como de pós-consumo e descarte.

\section{REFERÊNCIAS}

ASHBY, M. F. Materials and the Environment: Eco-informed Material Choice. 2nd. ed. Oxford: Butterworth-Heinemann, 2013.

ANATEL. Brasil fecha 2011 com recorde de habilitações na telefonia móvel. 16 de janeiro de 2012. Disponível em: http://www.anatel.gov.br/Portal/exibirPortalPaginaEspecialPesquisa.do?acao=\&tipoConteudoHtml=1\&codNoticia=24506. Acesso em 26 de novembro de 2018.

ANDRADE-LIMA, H. Gestão dos recursos e impactos socioambientais no ciclo de vida dos equipamentos eletroeletrônicos (EEE). Monografia (graduação), Centro de Ciências Biológicas, UFPE, 2012.

BRASIL. Lei $n^{\circ} 12.305$ de 2 DE AGOSTO DE 2010. Institui a Política Nacional de Resíduos Sólidos; altera a Lei no 9.605, de 12 de fevereiro de 1998; e dá outras providências. Diário Oficial [da] República Federativa do Brasil. Brasília, DF, ago. 2010. Disponível em: http://www.planalto.gov.br/ccivil_03/_Ato20072010/2010/Lei/L12305.htm. Acesso em 5 de novembro de 2018.

CADORE, E. Joalheria contemporânea e sustentabilidade: recuperação de metais e lapidação de vidros a partir de resíduos. Trabalho de conclusão de curso, Faculdade de Arquitetura, curso superior de Design de Produto, UFRGS, Porto Alegre, 2015.

CÂNDIDO, L. H. A.; KINDLEIN JÚNIOR, W.; PALOMBINI, F. L. Indicators for the feasibility of WEEE processing plants in Brazil: a relationship between virgin mineral copper ore and the recycling of consumer electronic products. Design \& Tecnologia, n. 09, p. 59-65, 2015.

CARVALHO, T.; XAVIER, L. Gestão de Resíduos

Eletroeletrônicos. 1. ed. Rio de Janeiro: Elsevier, 2014. CARVALHO, T.; XAVIER, L. Introdução à gestão de
Resíduos de Equipamentos eletroeletrônicos. In: Gestão de Resíduos Eletroeletrônicos. 1. ed. Rio de Janeiro, Elsevier, p. 17-34, 2014.

CHEN, M. et al. Electronic Waste Disassembly with Industrial Waste Heat. Environ. Sci. Technol, 47, 21, p. 12409-12416, 2013.

CIDADE, M. K. Design e tecnologia para a joalheria: microtomografia da gravação a laser $\mathrm{CO} 2 \mathrm{em}$ ágata e implicações para projetos com desenhos vetoriais. 2017. 106 f. Tese (Doutorado) - Universidade Federal do Rio Grande do Sul, Porto Alegre, 2017.

CIDADE, M. K.; PALOMBINI, F. L.; LIMA, N. F. F.; DUARTE, L. C. Método para determinação de parâmetros de gravação e corte a laser $\mathrm{CO} 2$ com aplicação na joalheria contemporânea. Design e Tecnologia, Porto Alegre, v. 6, n. 12, p. 54-64, 2016.

CORBETTA, G. Joalheria de Arte. Porto Alegre: AGE, 2007.

DOUGHERTY, B. Design Gráfico Sustentável. 1. ed. São Paulo: Rosari, 2011.

GOLA, E. A joia: história e design. São Paulo: Senac São Paulo, 2013.

HEATHER, A. Produtos. Disponível em: https:// ashleyheather.co.za/products/concrete-studs. Acesso em 26 de setembro de 2018.

HUABO, D. et al. Examining the technology acceptance for dismantling of waste printed circuit boards in light of recycling and environmental concerns. Journal of Environmental Management, v. 92, i. 3, p. $392-399,2011$.

IBGM - INSTITUTO BRASILEIRO DE GEMAS E METAIS PRECIOSOS. 0 setor em grandes números: situação atual e perspectivas do mercado interno e externo. Brasília: IBGM, 2012.

KASPER, A. C. et al. Printed wiring boards for mobile phones: Characterization and recycling of cooper. Waste Management, v. 31, i. 12, p. 2536-2545, 2011.

KLIAUGA, A. M.; FERRANTE, M. Metalurgia básica para ourives e designers: do metal à joia. São Paulo: Blücher, 2009.

LG. Coleta Inteligente. Disponível em https://www. Ig.com/br/suporte/coleta-seletiva. Acesso em 5 de novembro de 2018.

LÓPES, G. Crua Design Produtos. Disponível em: http://www.cruadesign.iluria.com/pd-4e0880-colar-geometria-n-5.html?ct=37473\&p=2\&s=1. Acesso em 26 de setembro de 2018.

MALESKI, F. et al. Reutilização de madeira de lei no processo de fabricação de joias. Mix Sustentável, 
Florianópolis, v.3, n. 3, p. 76 - 86, out./mar. 2017. MORAES, V.; ESPINOSA, D.; LUCENA, L. Tecnologias de tratamento para resíduos de equipamentos eletroeletrônicos. In: Gestão de Resíduos Eletroeletrônicos. 1. ed. Rio de Janeiro, Elsevier, p. 17-34, 2014.

MORENO, S. N. S.; CIDADE, M. K. Sustentabilidade e Joalheria: Reciclagem de Eps para Aplicação em Joias. MIX Sustentável, [S.I.], v. 5, n. 4, p. 27-39, nov. 2019.

MOTOROLA. Programa Logística Reversa. Disponível em https://www.motorolasolutions.com/ pt_xl/about/reverse-logistics-program.html. Acesso em 5 de novembro de 2018.

NIEMEYER, L. Elementos da semiótica aplicados ao design. Rio de Janeiro: 2AB Editora Ltda, 2003.

PALOMBINI, F. L.; CIDADE, M. K.; DE JACQUES, J. J. How sustainable is organic packaging? A design method for recyclability assessment via a social perspective: A case study of Porto Alegre city (Brazil). Journal of Cleaner Production, v. 142, p. 2593-2605, jan. 2017.

PREFEITURA DE SANTA MARIA. Pontos de Entrega Voluntária (PEV). Disponível em https://www.santamaria.rs.gov.br/noticias/15233-conheca-a-relacao-de-empresas-e-entidades-que-recebem-residuos-solidos-em-santa-maria. Acesso em 5 de novembro de 2018.

SÁ, V. Designer de joias gaúcha cria peças com prata extraída de raio-x usado. Disponível emhttps:// www.jornaldocomercio.com/_conteudo/2017/02/ge/ noticias/547573-designer-de-joias-gaucha-cria-pecas-com-prata-extraida-de-raio-x-usado.html. Acesso em 26 de setembro de 2018.

SAMSUNG. Programa de Reciclagem Samsung. Disponível em https://www.samsung.com/br/support/planet-first/. Acesso em 5 de novembro de 2018. SEPA- SWEDISH ENVIRONMENTAL PROTECTION AGENCY. Recycling and disposal of electronic waste-REPORT 6417. Bromma, Sweden March 2011. Acesso em 25 de novembro de 2018. Disponível em: http://www.naturvardsverket.se/Documents/publikationer6400/978-91-620-6417-4.pdf

SILVEIRA, $B$. Minidicionário da língua portuguesa. São Paulo: Editora FTD S.A., 2000.

TAKANORI, H. et al. Techniques to separate metal from waste printed circuit boards from discarded personal computers. Journal of Material Cycles and Waste Management, v. 11, p. 42 - 54, 2009.

VOGUE. Malgosia Kalinska. Disponível em: https:// www.vogue.it/en/vogue-gioiello/designer/2014/06/ malgosia-kalinska\#ad-image. Acesso em 26 de setembro de 2018.

WIDMER, R.; OSWALD KRAPF, H.; SINHA-KHETRIWAL, D.; SCHNELLMANN, M.; BONI, H. Global perspectives on e-waste. Environmental Impact Assessment Review, p. 436-458, 2005.

WACKERNAGEL, M.; REES, W. Our ecological footprint. Canadá: New Society Publishers, 1996.

YAN, L. et al. Precious metals recovery from waste printed circuit boards: A review for current status and perspective. Resources, Conservation and Recycling, v. 113, p. 29 - 19, 2016. 


\section{AUTORES}

ORCID: https://orcid.org/0000-0001-9411-2756

LÚCIO SILVA KIELING CINTRA I Universidade Federal de Santa Maria - UFSM | Desenho Industrial | Santa Maria-RS, Brasil | Correspondência para: Av. Roraima, 1000, prédio 40, sala 1136 | Email: lucioskcintra@gmail.com

ORCID: https://orcid.org/0000-0001-5893-383X

MARIANA KUHL CIDADE, Dra. I Universidade Federal de Santa Maria - UFSM | Departamento de Desenho Industrial | Santa Maria-RS, Brasil | Correspondência para: Av. Roraima, 1000, prédio 40, sala 1136 | Email: mariana.cidade@ufsm.br

\section{COMO CITAR ESTE ARTIGO}

CINTRA, Lúcio Silva Kieling; CIDADE, Mariana Kuhl. Reutilização e Reciclagem: Desenvolvimento de Joia com Componentes Oriundos de Resíduos Eletroeletrônicos. MIX Sustentável, [S.I.], v. 6, n. 3, p. 27-36, jun. 2020. ISSN 24473073. Disponível em:<http://www.nexos.ufsc.br/index.php/mixsustentavel>. Acesso em: dia mês. ano. doi:https://doi. org/10.29183/2447-3073.MIX2020.v6.n3.27-36. 